\section{Predispositional Effect of Soil Water Saturation on Infection of Chile Pepper by Phytophthora capsici}

\author{
S. Sanogo ${ }^{1}$ \\ State University, Las Cruces, NM 88003-0003 \\ Additional index words. Capsicum annum, phytophthora blight, flooding
}

Department of Entomology, Plant Pathology, and Weed Science, New Mexico

\begin{abstract}
Phytophthora capsici is a serious soilborne pathogen in chile pepper [Capsicum annuиm L.] in New Mexico, and has been shown to spread under high soil moisture conditions and cause losses in a wide array of crops worldwide. This study was conducted to assess whether soil water saturation predisposes chile pepper to infection by $P$. capsici. Potted chile pepper plants of 'Criollo de Morelos 334' ('CM334') and 'New Mexico 6-4' ('NM6-4'), resistant and susceptible to $P$. capsici, respectively, were subjected to soil water saturation conditions (saturated and nonsaturated) for 3 and 6 days at two growth stages (six- to eight-leaf stage and one- to four-flower bud stage) prior to being inoculated or noninoculated with zoospores of $P$. capsici. Regardless of growth stage, no disease symptoms developed in ' $\mathrm{CM334}$ ' grown either under saturated or nonsaturated soil conditions at any of the two periods ( 3 or 6 days) of soil water saturation. In 'NM6-4', disease symptoms consisting of stem necrosis, defoliation, and wilting were expressed. Plant growth stage at inoculation had a significant effect on disease severity $(P<0.0001)$. However, the response of 'NM6-4' to $P$. capsici at each growth stage under saturated soil conditions was similar to that under nonsaturated conditions regardless of the period of saturation $(P=0.09)$. These results indicate that soil water saturation does not exert a significant predispositional effect on infection of chile pepper by $P$. capsici.
\end{abstract}

Phytophthora blight, caused by Phytophthora capsici, was first described by Leonian (1922) as a disease affecting roots, stems, and fruit of chile pepper (Capsicum annuum L.). Infection of roots results in root rot and plant wilting. Brown to black lesions may develop on stems, and brown water-soaked lesions may be found on leaves and fruit. Since the publication of Leonian's work, the disease has been reported in a wide array of crops in plant families such as solanaceae and cucurbitaceae (Erwin and Ribeiro, 1996). Phytophthora blight is a serious disease on chile pepper, and was shown to decrease yield of green chile pepper by $55 \%$ and combined yield of green and red chile pepper by $36 \%$ (Xie et al., 1999).

Development of Phytophthora blight in pepper has been invariably associated with high soil moisture conditions as generated from irrigation or rainfall (Biles et al., 1992; Bowers and Mitchell, 1990; Bowers et al., 1990; Café-Filho and Duniway, 1995; Ristaino, 1991; Xie et al., 1999). The relationship between soil moisture and ecology of $P$. capsici in pepper has been extensively researched and knowledge accumulated in this area has been reviewed (Erwin and Ribeiro, 1996; Ristaino and Johnston, 1999). Bowers and Mitchell (1990) showed that plant mortality increased in pepper seedlings growing in soil infested with oospores of $P$. capsici and exposed to $24-\mathrm{h}$

Received for publication 12 Sept. 2005. Accepted for publication 21 Oct. 2005. The author thanks Steve Thomas and Carmen Sanogo for reviewing this manuscript. This research was funded by the NMSU Agricultural Experiment Station.

'E-mailssanogo@nmsu.edu. rot severity index was 4.8 (on a scale of 0 to 5 ) on alfalfa plants grown in saturated soil for $5 \mathrm{~d}$ before inoculation, whereas average root rot severity index was 2.5 on plants grown in unsaturated soil.

Chile pepper is produced predominantly in southern New Mexico where furrow irrigation is the most practiced method of irrigation (Skaggs et al., 2000). Saturated soil conditions are commonly encountered in chile pepper fields under furrow irrigation, and following midseason and late season rainfalls (Biles et al., 1992). However, it is not known whether predispositional effects occur in the interaction of chile pepper with $P$. capsici under saturated soil conditions.

The objective of this study was to assess the effect of soil water saturation on infection of chile pepper by $P$. capsici.

\section{Materials and Methods}

Inoculum preparation and plant production. Phytophthora capsici, isolate PWB-24 (Bosland and Lindsey, 1991), was used in this study, and inoculum was prepared as follows. Briefly, PWB-24 was grown on V8 juice-agar at $25{ }^{\circ} \mathrm{C}$. After $5 \mathrm{~d}$ of growth, six mycelial plugs (1 cm in diameter) were cut from the culture. The plugs were placed in $20 \mathrm{~mL}$ sterile distilled water in a petri dish and incubated at $25^{\circ} \mathrm{C}$ for $3 \mathrm{~d}$ for sporangia formation. The plates were then transferred to $10{ }^{\circ} \mathrm{C}$ for 60 min, and returned at $25^{\circ} \mathrm{C}$ for $90 \mathrm{~min}$. At this point, zoospores were produced and released into the water. The contents of each petri dish were passed through three layers of cheesecloth to remove agar plugs. The concentration of zoospores was assessed with a hemacytometer and adjusted to 2000 zoospores/mL.

Chile pepper cultivar 'New Mexico 6-4' (NM6-4) and chile pepper line 'Criollo de Morelos \#334' (CM334) were used in this study. Cultivar 'NM6-4' is susceptible to $P$. capsici, whereas 'CM334' is resistant (Bosland and Lindsey, 1991). Chile seeds were planted in six-cell plastic trays (with a cell dimension of 6,4 , and $6 \mathrm{~cm}$ in length, width, and depth, respectively) filled with sterilized Terra-Lite Metro Mix 360 (W. R. Grace \& Co., Memphis, Tenn.). At the fourth fully expanded true leaf stage, seedlings were transplanted into plastic pots (with a diameter of $10 \mathrm{~cm}$ on top and 7.5 $\mathrm{cm}$ on bottom, and a depth of $9 \mathrm{~cm}$ ) filled with sterilized Terra-Lite Metro Mix 360 at the rate of one seedling per pot. Seedlings were then fertilized by adding to each pot $150 \mathrm{~mL}$ solution of a $20 \% \mathrm{~N}-20 \% \mathrm{P}_{2} \mathrm{O}_{5}-20 \% \mathrm{~K}_{2} \mathrm{O}$ fertilizer (Scotts Co., Marysville, Ohio) containing $3.94 \%$ ammoniacal nitrogen, $6.05 \%$ nitrate, $10.01 \%$ urea, $0.05 \% \mathrm{Mg}, 0.0068 \% \mathrm{~B}, 0.0036 \%$ $\mathrm{Cu}$ (chelated $\mathrm{Cu}), 0.05 \% \mathrm{Fe}$ (chelated $\mathrm{Fe}$ ), $0.025 \% \mathrm{Mn}$ (chelated Mn), $0.0009 \% \mathrm{Mo}$, and $0.0025 \% \mathrm{Zn}$ (chelated Zn). Planting of seeds and transplanting of seedlings were staggered to produce plants at two phenological stages (six- to eight-leaf stage, and one- to four-flower bud stage).

Effects of soil water saturation on infection of chile pepper by Phytophthora capsici. At the six to eight-leaf stage and at the one- to 
four-flower bud stage, potted plants were subjected to varying levels of nonsaturated and saturated conditions in the greenhouse following procedures described by Kuan and Erwin (1980). Pots maintained under saturated conditions were placed on plant saucers (12.5 $\mathrm{cm}$ diameter, and $3.5 \mathrm{~cm}$ depth), which were kept full of tap water (electrical conductivity $=0.5 \mathrm{dS} \cdot \mathrm{m}^{-1}$ ) for 3 and $6 \mathrm{~d}$ before inoculation with $P$. capsici. No saucers were placed beneath pots maintained undernonsaturated conditions. In order to determine the effect of soil water saturation on plants in absence of the pathogen, a set of potted plants noninoculated with $P$. capsici were included in the experiment. There were 32 treatments generated from the combination of two soil water saturation conditions (saturated and nonsaturated), two periods of soil water saturation ( 3 and $6 \mathrm{~d}$ of saturated and nonsaturated conditions), two inoculum levels (no inoculum added and inoculum added to soil), two chile entries (susceptible and resistant to $P$. capsici), and two growth stages (six- to eight-leaf, and one- to four-flower bud stages). The 32 treatment combinations were evaluated in a split split-plot design, with inoculum levels as whole-plot factor, cultivar by growth stage as subplot factor, and soil water saturation (saturated and nonsaturated) by period ( 3 and 6 d) of soil water saturation as sub-subplot factor. Each treatment was replicated 5 times, with a potbeing a replication. Three additional potted plants were allocated to the 6 -d period of soil water conditions (with no inoculum added) and were used for assessment of plant stress as described below. The entire experiment was completed three times.

For plant inoculation, $5 \mathrm{~mL}$ of a zoospore suspension (2000 zoospores $/ \mathrm{mL}$ ) was dispensed onto the surface of the soil in each pot at about $2 \mathrm{~cm}$ away from the lower stem of each plant. For seedlings serving as controls (noninoculated), $5 \mathrm{~mL}$ of sterile water was dispensed on top of soil in each pot. The 6-d soil water saturation treatment was initiated $3 \mathrm{~d}$ before the $3-\mathrm{d}$ soil water saturation treatment to enable plant inoculation to be performed on the same day for all treatments. Plant inoculation was performed 30 min after soil water saturation treatments were terminated. Plants were watered once a day following inoculation.

Assessment of soil conditions, plant stress, and plant infection. Soil water potential was monitored in potted plants placed under both saturated and nonsaturated conditions using Watermark soil moisture sensors (Spectrum Technologies, Inc.). In plants at the six- to eight-leaf stage subjected to 6-d period of saturated and nonsaturated soil water conditions, chlorophyll content index and dry weight of above-ground plant parts were measured to assess whether plant stress was generated under the soil water saturation treatments. The 6-d period was selected to represent the extreme level of plant stress, and the six- to eight-leaf stage was chosen because previous studies, as summarized by Café-Filho and Duniway (1995), have shown that pepper is most susceptible to $P$. capsici at this stage. Leaf chlorophyll content index was measured using a CCM-200 chlorophyll-content meter (Opti-
Sciences, Tyngsboro, Mass.). Measurements were performed on the fourth fully expanded leaf from the shoot apex on each of the three additional plants (noninoculated) from saturated and nonsaturated treatments in the 6-d period of soil water condition as indicated previously. Stems from the three plants were cut at the crown, inserted individually in a brown paper bag, and placed in an oven at $65^{\circ} \mathrm{C}$. Dry weights were recorded after $48 \mathrm{~h}$. Plants were monitored for disease symptoms, and disease severity on above-ground plant parts was evaluated at $7 \mathrm{~d}$ (six- to eight-leaf stage) and $14 \mathrm{~d}$ (one- to four-flower bud stage) after inoculation using a scale modified from Ristaino (1990) as follows: $0=$ no visual disease symptoms, $1=$ stem necrosis with no girdling, $2=$ stem necrosis with girdling, $3=$ stem necrosis with $<50 \%$ defoliation, $4=$ stem necrosis with $>50 \%$ defoliation, $5=$ wilted, and $6=$ dead.

Statistical analysis. Data consisting of chlorophyll content index and dry weight of aboveground plant parts from each experiment were subjected to analysis of variance using Proc Mixed procedure in SAS (SAS Institute, Cary, N.C.). The data consisting of disease severity ratings were ordinal, therefore these data were analyzed by nonparametric approaches using SAS macros F2 LD_F1 and LD_CI as outlined by Brunner et al. $(2 \overline{0} 02)$. These macros allow computation of mean rank of treatments, relative treatment effects (RTE), 95\% confidence intervals for RTE, and ANOVA-type statistics for gauging the significance of main factors and the interactions among these factors. Data from individual experiments were analyzed separately to determine consistency of results among repetitions of experiments. When results were consistent among experiments and the error variances were homogeneous $(P>0.05)$, results from all repetitions of experiments were combined. Error variances were evaluated for homogeneity using procedures outlined by Gomez and Gomez (1984).

Table 1. Median, mean rank, relative treatment effects (RTE), and 95\% confidence intervals (CI) for RTE of severity ratings on 'New Mexico 6-4' in relation to inoculation with Phytophthora capsici, growth stage, and soil water saturation.

\begin{tabular}{lcccccc}
\hline & $\begin{array}{c}\text { Growth } \\
\text { Inoculation }\end{array}$ & $\begin{array}{c}\text { Soil water } \\
\text { stage }^{z}\end{array}$ & & $\begin{array}{c}\text { Rean } \\
\text { saturation }\end{array}$ & $\begin{array}{c}\text { Relative } \\
\text { treatment } \\
\text { effect }\end{array}$ & $\begin{array}{c}\text { 95\% CI } \\
\text { for RTE }\end{array}$ \\
\hline Inoculated & LS68 & NS-3D & 4 & 203.37 & 0.845 & $(0.822,0.865)$ \\
& & NS-6D & 5 & 209.77 & 0.872 & $(0.860,0.883)$ \\
& & S-3D & 5 & 209.77 & 0.872 & $(0.852,0.888)$ \\
& S-6D & 5 & 218.93 & 0.910 & $(0.886,0.928)$ \\
& FB14 & NS-3D & 2 & 151.6 & 0.629 & $(0.602,0.656)$ \\
& & NS-6D & 2 & 149.63 & 0.621 & $(0.598,0.645)$ \\
& & S-3D & 2 & 149.63 & 0.621 & $(0.598,0.645)$ \\
& & S-6D & 2 & 151.3 & 0.628 & $(0.601,0.654)$ \\
& NS-3D & 0 & 60.5 & 0.250 & $(0.250,0.250)$ \\
& LS68 & NS-6D & 0 & 60.5 & 0.250 & $(0.250,0.250)$ \\
& & S-3D & 0 & 60.5 & 0.250 & $(0.250,0.250)$ \\
& & S-6D & 0 & 60.5 & 0.250 & $(0.250,0.250)$ \\
& FB14 & NS-3D & 0 & 60.5 & 0.250 & $(0.250,0.250)$ \\
& & NS-6D & 0 & 60.5 & 0.250 & $(0.250,0.250)$ \\
& & S-3D & 0 & 60.5 & 0.250 & $(0.250,0.250)$ \\
& S-6D & 0 & 60.5 & 0.250 & $(0.250,0.250)$ \\
\hline
\end{tabular}

${ }^{2}$ LS68 = six- to eight-leaf stage, FB14 = one- to four-flower bud stage.

${ }^{y} \mathrm{~S}=$ saturated, $\mathrm{NS}=$ nonsaturated conditions, $3 \mathrm{D}=3 \mathrm{~d}$, and $6 \mathrm{D}=6 \mathrm{~d}$.

${ }^{x}$ Disease severity was rated using the following scale: $0=$ no visual disease symptoms, $1=$ stem necrosis with no girdling, $2=$ stem necrosis with girdling, $3=$ stem necrosis with $<50 \%$ defoliation, $4=$ stem necrosis with $>50 \%$ defoliation, $5=$ wilted, and $6=$ dead. 
significant (Table 2; $P=0.092$ ).

In plants (noninoculated with $P$. capsici) at six- to eight-leaf stage and subjected to 6 -d soil water saturation, dry weight of above-ground plant parts (Table 3 ) was not significantly affected by soil water condition $(P=0.5366)$. Chlorophyll content index (Table 3) was greater under saturated conditions than under nonsaturated conditions $(P=0.0173)$. There was no discernable difference in plant appearance, such as leaf chlorosis, whether plants were subjected to saturated or nonsaturated soil conditions. Water potential varied from -0.0055 to $-0.0065 \mathrm{MPa}$ in pots placed in plant saucers (saturated conditions), and from -0.008 to $-0.020 \mathrm{MPa}$ in pots not placed in plant saucers (nonsaturated conditions). These values of water potential are well within those recorded with the same type of sensors in chile pepper fields fluctuating between -0.006 and -0.017 $\mathrm{MPa}$ during furrow irrigation events.

The data on dry weight of above-ground plant parts and chlorophyll content index suggest that there is no significant plant stress under excessive soil moisture conditions. However, other studies have reported the existence of plant stress as gauged by leaf chlorosis and reduction in plant growth (Hasnain and Sheikh, 1976; Sundstrom and Pezeshki, 1988). Hasnain and Sheikh (1976) exposed pepper plants to flooded conditions for 6 weeks, and reported leaf chlorosis and decrease in growth in plants under flooded conditions relative to plants under nonflooded conditions. Sundstrom and Pezeshki (1988) observed that leaves of bell pepper plants flooded for $96 \mathrm{~h}$ appeared chlorotic compared to nonflooded plants. In both of these studies, however, no quantitative data on chlorophyll content in the different treatments were provided. The difference between this work and other studies (Hasnain and Sheikh, 1979; Sundstrom and Pezeshki, 1988) may be attributable to differences among cultivars

Table 2. Analysis of disease severity ratings on 'New Mexico 6-4' in relation to inoculation with Phytophthora capsici, growth stage, and soil water saturation.

\begin{tabular}{lclcc}
\hline & \multicolumn{4}{l}{ ANOVA-type statistics } \\
\cline { 2 - 5 } Factor & Fn & df1 & df2 & $P$ value \\
\hline Inoculation (I) & 4410.7 & 1 & 22.23 & $<0.0001$ \\
Growth stage (G) & 274.90 & 1 & 22.23 & $<0.0001$ \\
Saturation (S) & 2.710 & 2.7 & $\infty$ & 0.09 \\
$\mathrm{I} \times \mathrm{G}$ & 274.90 & 1 & 22.23 & $<0.0001$ \\
$\mathrm{I} \times \mathrm{S}$ & 2.710 & 2.7 & $\infty$ & 0.09 \\
$\mathrm{G} \times \mathrm{S}$ & 2.710 & 2.7 & $\infty$ & 0.092 \\
$\mathrm{I} \times \mathrm{G} \times \mathrm{S}$ & 2.710 & 2.7 & $\infty$ & 0.092 \\
\hline
\end{tabular}

${ }^{\mathrm{z}} \mathrm{Fn}$ is an ANOVA-type statistic equivalent to an F value with estimated degrees of freedom df1 (numerator) and df2 (denominator). The significance of main factors and interactions among these factors is gauged by the $P$ values.

Table 3. Effect of soil water saturation on mean dry weight of above-ground plant parts and mean chlorophyll content index of chile pepper cultivars 'CM334' and 'NM6-4' noninoculated with Phytophthora capsici.

\begin{tabular}{|c|c|c|c|}
\hline Cultivar & $\begin{array}{l}\text { Soil water } \\
\text { saturation }^{z}\end{array}$ & $\begin{array}{l}\text { Mean dry } \\
\text { wt }(\mathrm{SE})^{\mathrm{y}}\end{array}$ & $\begin{array}{l}\text { Mean chlorophyll } \\
\text { content index }(\mathrm{SE})^{\mathrm{x}}\end{array}$ \\
\hline \multirow[t]{2}{*}{$\overline{\mathrm{CM} 334}$} & $\mathrm{~S}$ & $0.22(0.01)$ & $32.96(0.91)$ \\
\hline & NS & $0.21(0.01)$ & $26.1(0.46)$ \\
\hline \multirow[t]{2}{*}{ NM6-4 } & $\mathrm{S}$ & $0.60(0.07)$ & $28.05(0.64)$ \\
\hline & NS & $0.63(0.03)$ & $26.28(0.56)$ \\
\hline
\end{tabular}

${ }^{\mathrm{z}} \mathrm{S}=$ saturated, $\mathrm{NS}=$ nonsaturated, for $6 \mathrm{~d}$.

${ }^{y}$ Numbers in parentheses are standard error (SE) of the means.

${ }^{\mathrm{x}}$ Numbers in parentheses are standard error (SE) of the means. that the resistant line 'CM334' did not display any disease symptom indicates that high soil moisture conditions do not exert a significant predispositional effect on chile plants. In addition, the response of the susceptible 'NM6-4' to $P$. capsici was not differentially substantial between saturated and nonsaturated conditions at each growth stage.

Several inoculation methods are conceptually applicable to studies such as the one described herein. One method consists of burying mycelium plugs from pathogenic cultures in soil (Bernhardt and Grogan, 1982). This method is easy to perform, but may lead to nonuniform level of inoculum among pots because sporangia formation and zoospore release from these sporangia may be differentially affected by variation in soil conditions (Bernhardt and Grogan, 1982). A sound remedial methodological approach is to inoculate plants with known level of pathogenic propagules which are readily germinable. Such approach, which was used in this study and adopted by others (Kuan and Erwin, 1980), has the benefit of disentangling pathogenic factor from predispositional effect of soil water saturation on chile pepper infection by $P$. capsici. The level of inoculum used mirrored those used in other studies (Bosland and Lindsey, 1991).

In summary, findings from this work provide new information on the relationship between soil moisture and development of plant diseases caused by P. capsici. Data obtained suggest that soil water saturation does not impose a significant predispositional effect on chile pepper leading to increased infection by P. capsici. An outcome of this study is that it provides further understanding of the behavior of $P$. capsici under saturated soil conditions.

\section{Literature Cited}

Bernhardt, E.A. and R.G. Grogan. 1982. Effect of soil matric potential on the formation and indirect germination of sporangia of Phytophthora parasitica, $P$. capsici, and P. cryptogea. Phytopathology 72:507-511.

Biles, C., D.L. Lindsey, and C.M. Liddell. 1992. Control of phytophthora root rot of chile peppers by irrigation practices and fungicides. Crop Prot. 11:225-228.

Bosland, P.W. and D.L. Lindsey. 1991. A seedling screen for Phytophthora root rot of pepper, Capsicum annuum. Plant Dis. 75:1048-1050.

Bowers, J.H. and D.J. Mitchell 1990. Effect of soil-water potential and periodic flooding on mortality of pepper caused by Phytophthora capsici. Phytopathology 80:1447-1450.

Bowers, J.H., R.M. Sonoda, and D.J. Mitchell 1990. Path coefficient analysis of the effect of rainfall variables on the epidemiology of Phytophthora blight of pepper caused by Phytophthora capsici. Phytopathology 80:1439-1446.

Brunner, E., S. Domhof, and F. Langer. 2002. Nonparametric analysis of longitudinal data in factorial experiments. John Wiley \& Sons, Inc., New York.

Café-Filho, A.C. and J.M. Duniway. 1995. Effects of furrow irrigation schedules and host genotype on phytophthora root rot of pepper. Plant Dis. 79:39-43.

Erwin, D.C. and O.K Ribeiro. 1996. Phytophthora diseases worldwide. Amer. Phytopathol. Soc., St. Paul, Minn. 
Gomez, K.A. and A.A. Gomez. 1984. Statistical procedures for agricultural research. 2nd ed. John Wiley \& Sons, Inc., New York.

Hasnain, S. and K.H. Sheikh. 1976. Effects of flooding and drainage on the growth of Capsicum annuum L. Biologia 22:89-106.

Kim, Y.L., B.K. Hwang, and K.W. Park. 1989. Expression of age-related resistance in pepper plants infected with Phytophthora capsici. Plant Dis. 73:745-747.

Kuan, T.L. and D.C. Erwin. 1980. Predisposition effect of water saturation of soil on phytophthora root rot of alfalfa. Phytopathology 70:981-986.

Leonian, L.H. 1922. Stem and fruit blight of chiles caused by Phytophthora capsici sp. nov. Phytopathology 12:401-408.
Matheron, M.E., and M. Porchas. 2002. Suppression of phytophthora root and crown rot on pepper plants treated with acibenzolar-S-methyl. Plant Dis. 86:292-297.

Reifschneider, F.J.B., L.S. Boiteux, P.T. Della Vecchia, J.M. Poulos, and N. Kuroda. 1992. Inheritance of adult-plant resistance to Phytophthora capsici in pepper. Euphytica 62:45-49.

Ristaino, J.B. 1990. Intraspecific variation among isolates of Phytophthora capsici from pepper and curcubit fields in North Carolina. Phytopathology 80:1253-1259.

Ristaino, J.B. 1991. Influence of rainfall, drip irrigation, and inoculum density on the development of phytophthora root and crown rot epidemics and yield in bell pepper. Phytopathology 81:922-929.
Ristaino, J.B., and S.A. Johnston. 1999. Ecologically based approaches to management of Phytophthora blight on bell pepper. Plant Dis. 83:1080-1089.

Skaggs, R., M. Decker, and D. VanLeeuwen. 2000. A survey of southern New Mexico chile producers: Production practices and problems. New Mex. Agr. Expt. Sta. Tech. Bul. 782.

Sundstrom, F.J., and S.R. Pezeshki. 1988. Reduction of Capsicum annum $\mathrm{L}$. growth and seed quality by soil flooding. HortScience 23:574-576.

Xie, J., E.S. Cardenas, T.W. Sammis, M.M. Wall, D.L. Lindsey, and L.W. Murray. 1999. Effects of irrigation method on chile pepper yield and phytophthora root rot incidence. Agr. Water Mgt. 42:127-142. 